\title{
Post Tensioned CFRP tubes for improved energy absorption
}

DOI : 10.36909/jer.12501

\author{
Venkateswarlu Gattineni*, Venukumar Nathi \\ Department of Mechanical Engineering, GITAM School of Technology, Hyderabad, India \\ *Corresponding Author: ammu.abhi.sammi@gmail.com
}

\begin{abstract}
Thin-walled tubes made of CFRP (Carbon fiber reinforced Polymer) are being increasingly used as CC (Crush Cans) due to their higher specific energy absorption capacity in the automotive domain for absorbing impact energy during a frontal crash. Finite element analysis (FEA) based computational methods have matured over the years with increased accuracy and acceptable correlation with experimental results. FEA-based computational studies when used appropriately can reduce the number of physical tests and prototypes required besides accelerating the overall cycle design time. The present work proposes an FEA based design validation approach for the evaluation of post-tensioned crush can design that can absorb more impact energy compared to a normal CFRP thin tube. The FEM based method uses a combination of multiple simulation techniques to predict the behavior of a post-tensioned tube. The post-tensioning in the present work has been proposed in the form of internal pressure for the thin tube. It was found that a safe value of pressure, when applied as a post-tensioning load, can improve the energy absorption capacity without increasing the weight of the tube.
\end{abstract}

Key words: Post Tension, Inertia relief, Implicit, Explicit

\section{INTRODUCTION}

Across the globe, there are intense efforts to make designs weigh lighter and the Automotive domain is no exception. As a result, to achieve a lightweight vehicle many of the traditional steel components (Park CK et al., 2013, Hammarberg S, et al., 2020) and panels in a vehicle are replaced by different materials such as ultrahigh strength steel, Aluminum, Titanium, Plastics, and CFRP. Plastics and CFRP are used for vehicle parts that do not have exposure to heat from the engine and exhaust. Lightweight vehicle consumes less fuel and helps reduce carbon emissions. Among the nonmetals, CFRP is being increasingly used for vehicle panels in place of steel Sheetmetal. One of the major drawbacks of the CFRP component is that they must be completely replaced upon failure due to impacts. Hence CFRP is mostly used for parts (Park CK 
et al., 2013) which must fail by absorbing energy completely such as crush cans (CC). Impact during an accident or a crash generates a compressive force on the $\mathrm{CC}$, which is expected to get crushed longitudinally, without buckling laterally (TJ Reddy et al., 2019). There exists a host of parameters to describe the performance of CC (TJ Reddy et al., 2019). Among them, the most important is specific energy absorption (SEA), which is nothing but the energy absorption capacity for unit mass. CFRP material being low in density is expected to have better SEA compared to those of metallic designs. Metallic CC typically absorbs energy inelastic, plastic, and damage modes (TJ Reddy et al., 2017). But CFRP CC absorbs energy in elastic and damage modes, owing to the brittle nature of the material (TJ Reddy et al., 2017). Post-tensioning is the process of inducing stress in the direction opposite to the occurrence of load in the operating conditions after the part or component or system is made/manufactured (Veerat S et al., 2018). Circular holes are introduced in reinforced concrete structures during the manufacturing stage followed by the insertion of steel rods. The steel rods are held on one side firmly and then pulled from the other side in tension mode. Upon the rods getting stressed, holes are closed on either side with suitable capping arrangements, leaving the rods in a pre-stressed state. The holes are positioned in such a way that the rods get stressed and introduce a pre-stress in the concrete (Veerat S et al., 2018) in the direction opposite to that of the loads that the concrete structure is likely to experience. As a result, when the concrete structure experiences the actual load, some of the portions of the load gets consumed to overcome the pre-stress. As a result, the structure experience fewer loads compared to the applied/experienced load. This way, the post-tensioned design shall be leaner than the conventional designs to bear the same applied load. Also, as can be seen from literature (W. Werchniak,1972, Zhang C et al., 2018), historically both for metals and anisotropic materials induced prestress seem to be offering improved performance towards fracture and associated damage-based energy absorption criteria.

Thin tubes or cylinders when subjected to uniform internal pressure experience three different types of stresses namely (Khurmi RS et al., 2018). radial pressure (This is equivalent to the

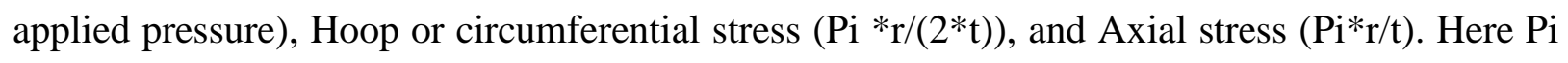
is the internal pressure applied, $r$ is the inner radius of the tube and $t$ is its thickness. Hence if a thin tube is subjected to pressure it experiences an axial pressure which shall be tensile. When such a tube is used as a CC, the compressive impact load due to a crash or accident needs to first overcome the tensile stress that is induced due to pressure. As a result, the post-tensioned tube can absorb more energy compared to a normal tube (With no internal pressure). The strain due to 
the longitudinal stress $(\mathrm{Pi} * \mathrm{r} /(2 * \mathrm{t}) / \mathrm{E})$ tries to elongate the thin tube. This elongation (Pi $\left.*_{\mathrm{r}} /(2 * \mathrm{t}) / \mathrm{E}^{*} \mathrm{~L}\right)$ opposes the crush of the tube, which has to be over come with additional energy, during sacrificial failure.

Previous experimental studies in the aerospace domain have revealed that thin tubes when internally pressurized and used in an aircraft bottom compartment, exhibit improved energy absorption capacity (T.Hou et al., 2014) compared to unpressurized tubes. Another study also revealed that the damage initiation load increases for a pre-stressed tube compared to a normal tube, both of which are made of CFRP material with quasi-isotropic configuration (V Gattineni et al., 2020) Any design is normally an iterative process (Shigley JE et al., 2011) and hence the studies related to design validation must be repeated for each iteration. The method of design validation can be either by using classical methods (Solid Mechanics) or experimental methods or finite element methods (FEM). Solid Mechanics methods can only be applied to certain designs that have certain shapes and use specific materials. Experimental methods need prototypes and testing equipment/facilities. On the other hand, FEM based methods as implemented in commercial software like Abaqus can be used to evaluate the designs of any shape and material without the need to have a physical model. As a result, the FEM based design validation process is fully digital and does not lead to any destructive testing. Changes in design can be rapidly implemented to computer-based designs and quickly validated. This leads to a rapid reduction of the lead time required for the design life cycle. The present work proposes FEM based method to validate the design of a quasi-isotropic post-tensioned CC design. First, the FEM software Abaqus is calibrated against the experimental results to study its ability to simulate the energy absorption process in a thin CFRP tube. Later the software is also calibrated using the solid mechanics approach to predict the stresses in the same tube when subjected to internal pressure.

\section{TUBE DETAILS USED FOR THE STUDY}

A thin CFRP tube configuration with an inner radius of $25 \mathrm{~mm}$ and 9 layers each with a thickness of $0.19 \mathrm{~mm}$ and a length of $60 \mathrm{~mm}$ as available in the literature (Guohua Zhu et al., 2018) is chosen for the study. To achieve a quasi-isotropic configuration, ply angles of $0^{\circ}, 90^{\circ}, 0^{\circ}, 90^{\circ}$, $0^{\circ}, 90^{\circ}, 0^{\circ}, 90^{\circ}, 0^{\circ}$ have been used. The schematic of the tube is as shown in Figure 1. 


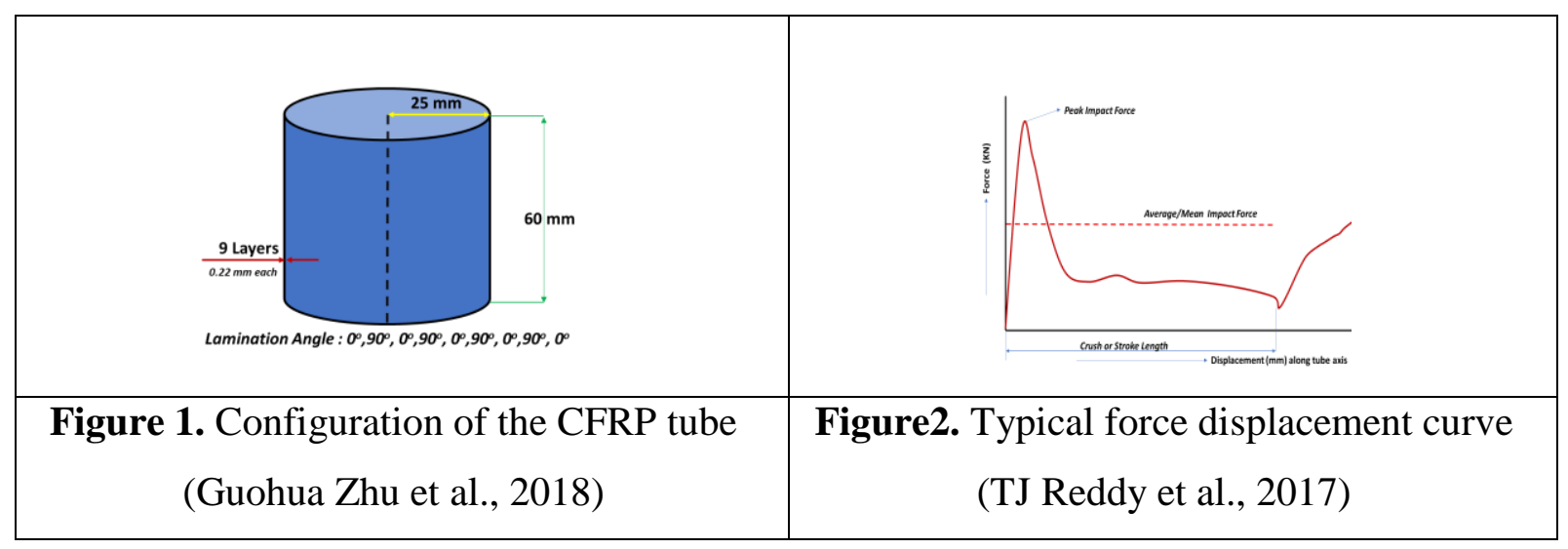

\section{TRIGGER EOMETRIC CONFIGURATION}

The area under the force-displacement curve for a compressed tube gives the energy absorbed by it during an impact. The force-deflection curve could be different for different speeds of impact. A typical force-displacement curve for a CC is shown in Figure 2. As can be seen from the Figure, for an ideal CC the peak impact force must be equal to the mean value of impact force in the force-displacement curve. CFRP materials are usually very stiff compared to metals and hence shall exhibit a very high value of initial peak force which shall be very high compared to the mean force (Yan Ma et al., 2018). To reduce the initial peak force, the edge of the tubes is usually modified with features called triggers (Yan Ma et al., 2018., Deepak S et al., 2018). There could be several trigger configurations. But to avoid accidental failure of the tube due to slow speed impacts and for ease of manufacturing a double bevel trigger configuration as suggested in the literature (Gattineni V et al., 2020) has been used for the current geometry. The trigger angle used is $45^{\circ}$. Figure 3 shows the schematic cross-section of the tube thickness for the trigger configuration used.

\section{MATERIAL PROPERTIES USED FOR THE STUDY}

CFRP is a brittle material by nature. Hence the typical stress-strain curve for a CFRP material used as an energy-absorbing component is as shown in Figure 4. 


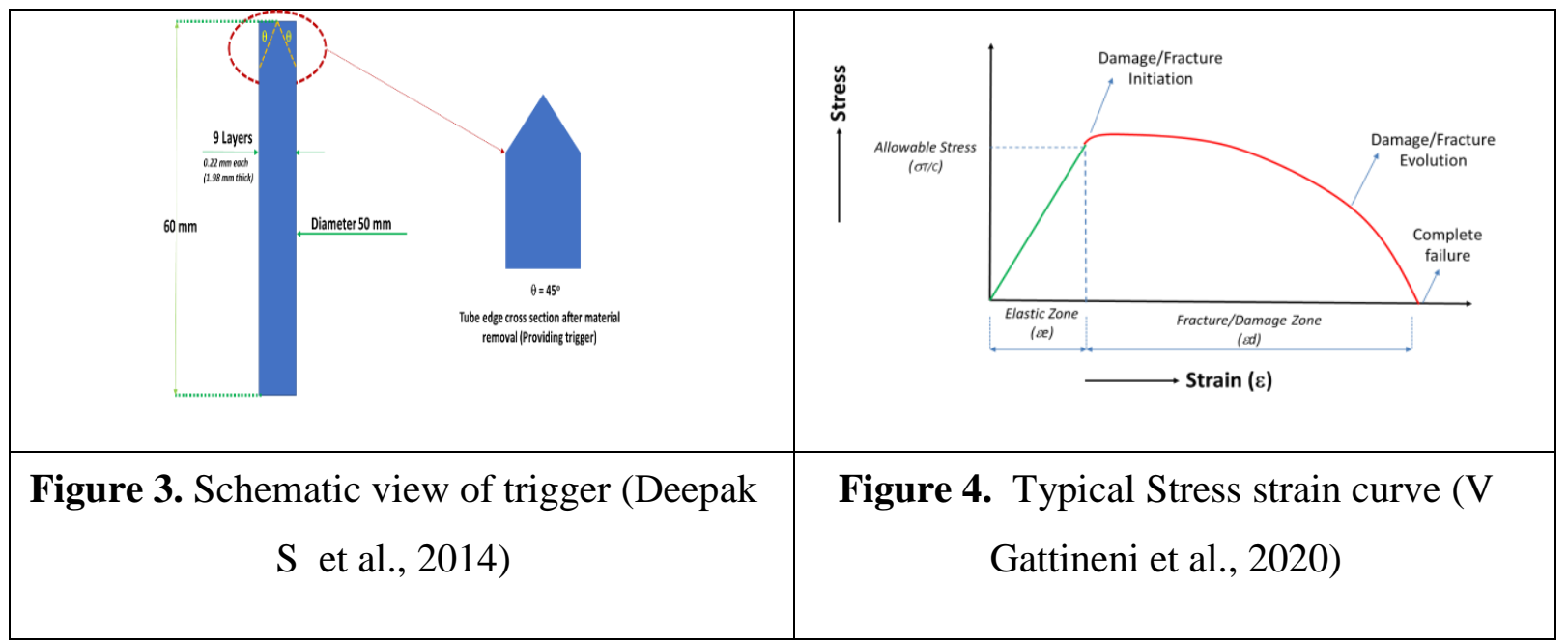

Hence for design validation of components made of CFRP the elastic material properties as shown in Table 1 (Guohua Zhu et al., 2018) have been used. Upon loading, as and when the interactive stress value in the component reaches an allowable limit, the damage gets initiated in the component. The limiting values for the damage to get initiated are as shown in table 2 (Guohua Zhu et al., 2018). Once the damage gets initiated, further incremental loading causes damage to evolve further to make it fail. The total energy that is absorbed during the damage process until complete failure is termed as fracture energy. The fracture energy data for the material being used for the study are listed in Table 2 (Guohua Zhu et al., 2018)

Table 1. Density and Elastic material properties used for study (Guohua Zhu et al., 2018)

\begin{tabular}{|c|l|l|l|}
\hline S.No & \multicolumn{1}{|c|}{ Property Name } & \multicolumn{1}{|c|}{ Value } & \multicolumn{1}{|c|}{ Allowable } \\
\hline 1 & Density & $1560 \mathrm{Kg} / \mathrm{m} 3$ & \\
\hline 2 & Elastic modulus Primary & $65500 \mathrm{~Pa}$ & 776 Tensile \& 704 Compressive (MPa) \\
\hline 3 & Elastic modulus Secondary & $64400 \mathrm{~Pa}$ & 760 Tensile \& 698 Compressive (MPa) \\
\hline 4 & Shear modulus & 4500 Pascal & $95(\mathrm{MPa})$ \\
\hline 5 & Poisson's ratio & 0.037 & \\
\hline
\end{tabular}




\begin{tabular}{|c|l|c|c|c|}
\hline \multicolumn{5}{|c|}{ Table 2. Fracture energy data used for the study (Guohua Zhu et al., 2018) } \\
\hline S.No & \multicolumn{1}{|c|}{ Property Name } & Tensile & Compressive & Units \\
\hline 1 & $\begin{array}{l}\text { Fiber fracture energy } \\
\text { (Primary axis) }\end{array}$ & 125 & 250 & $\mathrm{KJ} / \mathrm{m} 2$ \\
\hline 2 & $\begin{array}{l}\text { Fiber fracture energy } \\
\text { (Secondary axis) }\end{array}$ & 95 & 245 & $\mathrm{KJ} / \mathrm{m} 2$ \\
\hline
\end{tabular}

\section{TOOL SELECTION AND CALIBRATION FOR FEM STUDY}

The post-tension design of the thin CFRP tube that needs to be studied shall get subjected to internal pressure (As part of the post-tensioning approach) load followed by a compressive load. Hence the FEM tool to be chosen should simulate the behavior of the CFRP tube when subjected to pressure and compressive loads. Multiple thin tube configurations (With different areas of cross-sections) have been studied (Guohua Zhu et al., 2018) through the FEM method using Abaqus software (Abaqus., Simulia Corp) All the tube configurations were made of the same CFRP material. All the design configurations were also tested physically. The physical tests and FEM studies were conducted considering steady-state static loading. The studies have a good correlation between experiments and physical tests. Studies have revealed that either hexagonal or circular cross-sections for tubes are well suited as energy absorbers (Tuljapure, S.B et al., 2013). But from a manufacturing feasibility point of view, circular sections are easy to make compared to hexagonal sections. Hence the circular tubular cross-section which correlates with the test and FEM study using Abaqus has been used for the study (For the current study). As can be seen from the references (Guohua Zhu et al., 2018) the results of the FEM study using Abaqus software (Abaqus., Simulia Corp) correlate well with theoretical values, for a thing tube subjected to internal pressure load. Hence Abaqus software is suitable to correctly simulate the behavior of thin CFRP tubes subjected to internal pressure followed by crushing through compression.

\section{APPROACH USED FOR FEM STUDY}

To study the effect/improvement of post-tension compared to the regular tube, first, a normal CFRP tube is compressed, and its energy absorption capacity is computed. Later, the same tube design is first subjected to internal pressure and allowed to bulge (radially) and expand (Along the axis) under the influence of internal pressure load to experience stress. The tube under stress 
is then compressed to estimate the energy absorption capacity. The detailed approach for the study has been shown in the form of a flow chart in Figures 5 and 6.

\section{FAILURE THEORY USED FOR THE STUDY}

To assess the failure of the designs or components made up of CFRP multiple theories of failure are used by engineers globally (maximum stress, maximum strain, maximum shear stress, interactive stress). Interactive failure criteria that consider the interaction between stress/strain tensors in a different direction are found to predict failure close to physical tests. Among the interactive theories, the Hashin criteria (Hashin et al., 1980) is found to be more accurate (Sun C.T et al., 1996) as per research. Hence the same criteria have been used for the present study.

\section{FINITIE ELEMENT MODEL OF THE CFRP TUBE}

The thin tube has been modeled using a layered composite element available in Abaqus. To achieve this, a surface model representing the mid surface of the tube is created. The surface has been discretized using layered elements. Successive layers within the element starting from the inner most layers have been specified ply angles of $0^{\circ}, 90^{\circ}, 0^{\circ}, 90^{\circ}, 0^{\circ}, 90^{\circ}, 0^{\circ}, 90^{\circ}, 0^{\circ}$ to achieve quasi-isotropic configuration. All 9 layers have been assigned with the same thickness value of $0.22 \mathrm{~mm}$ per layer. To create the effect of trigger (double bevel), the length of each layer is adjusted as shown in Figure 7. Figure 8 shows the FE model of the thin CFRP tube in full and zoomed view of the trigger.
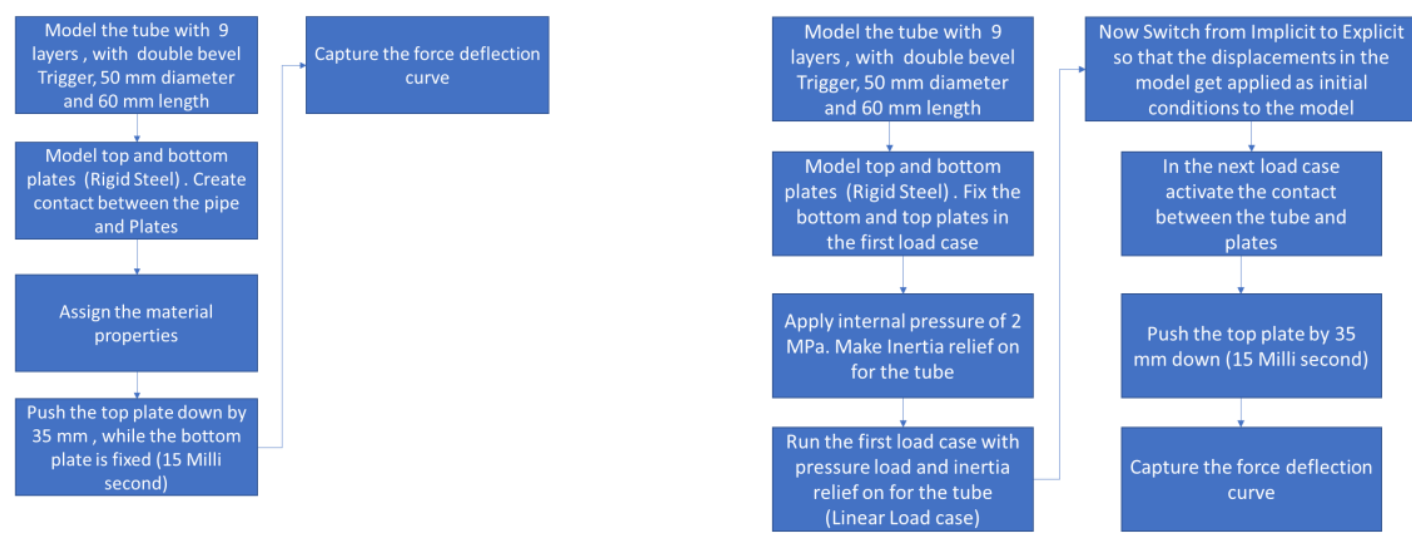
Figure 5. FEM based approach for energy absorption estimation of normal tube

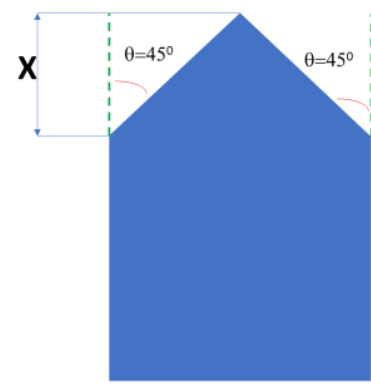
$9 * 0.22 X$ Thick

Layer Length : Trigger details

- $1^{\text {st Layer Height : } 60-x}$

- $2^{\text {nd }}$ Layer Height: $60-0.75 \mathrm{X}$

- $3^{\text {rd }}$ Layer Height: $60-0.50 X$

- $4^{\text {th }}$ Layer Hight : $60-0.25 \mathrm{X}$

- $5^{\text {th }}$ Layer Hight : 60

- $6^{\text {th }}$ Layer Hight : 60-0.25X

- $7^{\text {th }}$ Layer Hight : $60-0.50 \mathrm{X}$

- $8^{\text {th }}$ Layer Hight: 60-0.75x

- $9^{\text {th }}$ Layer Hight: $60-X$

$\mathrm{X}=$ Thickness of each layer $=0.22 \mathrm{~mm}$

Figure 7. Length of each layer in CFRP tube along the axis for double bevel trigger
Figure 6. FEM based approach for energy absorption in post tensioned tube

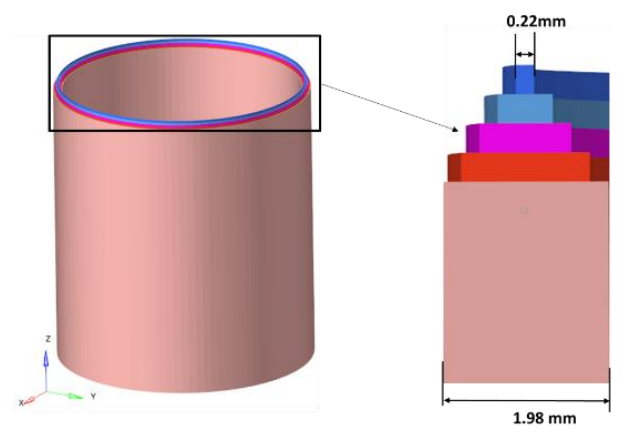

Figure 8. FE model used for the study (Surface)

\section{FE MODEL SETUP FOR THE BASE DESIGN STUDY}

The normal thin CFRP tube design is termed as the base design and is studied for energy absorption capacity at steady state using Abaqus software. For the FE model created, a rigid plate is attached at the bottom (bottom plate). This plate is fixed/grounded to prevent it from moving in any direction. A contact surface is created between the bottom surface of the tube and the bottom plate. Another rigid plate (top plate) is attached at the top of the tube (Edge with trigger). A contact surface is created between the top plate and top surface of the tube which has a trigger. The top plate is constrained in all directions, except for the axial direction of the tube. To simulate the steady-state compression of the base design for energy absorption, a downward displacement of $35 \mathrm{~mm}$ (Guohua Zhu et al., 2018) is prescribed for the top plate for 15 milliseconds. The model configuration is as shown in Figure 9. Since this is an impact scenario, explicit dynamics solver available within Abaqus (Abaqus., Simulia Corp) has been used. 


\section{FE MODEL SETUP FOR THE POST TENSION DESIGN STUDY}

To induce the pre-stress through the post-tension approach, the tube needs to be subjected to a pressure load first. Later to study the effect of pre-stress on the tube, the pre-stressed tube needs to be compressed to the same length as in the base case.

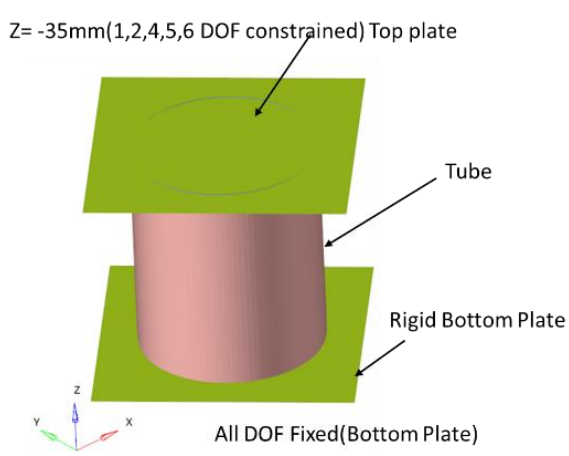

Figure 9. FE model used for the study (Surface)

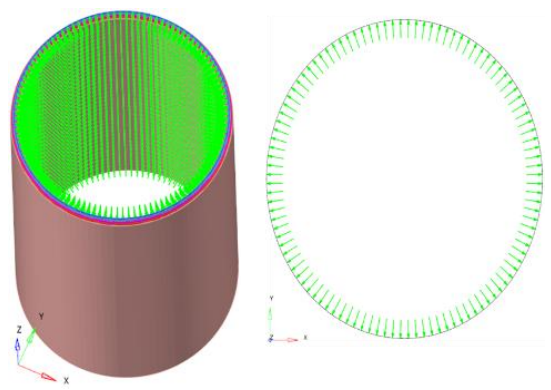

Figure 10. FE model used for post tensioning (pressure load)

\section{SAFE VALUE OF PRESSURE}

Theoretically, it is possible to apply an internal pressure up to $6 \mathrm{MPa}$ (Gattineni V et al., 2020) without causing burst failure of the tube. In the practical environment, a pressure value of $6 \mathrm{MPa}$ (Gattineni V et al., 2020) can cause the crushed pieces of CFRP tube during compression to fly around cause injury. Hence a safe pressure value of 2 MPa (T.Hou et al., 2018, Gattineni V et al., 2020) has been considered for the study.

\section{D'ALEMBERT'S PRINCIPLE FOR PRESSURE LOAD EFFECTS}

The same FE model of the thin CFRP used for the base design has been used to study the effect of pressure. But the top and bottom plates are not used. Normal FE based calculations/simulation requires the model to be fully constrained at least at one location. But if the model is constrained at one location, it can lead to high local stress (as the pipe cannot expand at the constrained location due to pressure application) which is not a real condition. Hence to avoid this issue, pressure loading in conjunction with the inertia relief method (which is based on d'alembert's principle) is used in Abaqus. This approach can solve a steady-state static FE model without boundary conditions without the need for fully constraining it. In this approach, an equivalent 
acceleration is applied at the center gravity of the body (tube) which is not constrained fully in the direction opposite to that of the load to achieve equilibrium. As a result, the component remains stationary even in the absence of full constraints. Hence the tube is subjected to pressure load invoking inertia relief and solved using implicit solver to induce the pre-stress in the tube. Figure 10 shows the FE model with the pressure load applied.

\section{ENERGY ABSORPTION CAPACITY OF THE POST TENSIONED TUBE/DESIGN}

The displacements predicted for the tube under the influence of pressure load are transferred to the model used for the base case (With top and bottom plates). The displacements at various nodes of the tube are specified as initial conditions for the base design tube. Like in the case of base design, the tube with displacements from pressure load specified as initial conditions is then compressed by $35 \mathrm{~mm}$ (same as in the case of the base case) and the energy absorption capacity is computed.

\section{RESULTS FOR BASE DESIGN STUDY}

Figures 11 shows the stress state of the CFRP tubes for compression of $35 \mathrm{~mm}$, for the base design. Figure 12 shows the force-displacement curve for the base design while the same figure also shows the graph of energy absorbed by the base design due to compression.

\section{RESULTS FOR POST TENSIONED DESIGN}

Figure 13 shows the stress state of the CFRP tubes for compression of $35 \mathrm{~mm}$, for the posttensioned design. Figure 14 shows the force-displacement curve for the post-tensioned design while the same figure graphically shows the energy absorbed by the post-tensioned design due to compression.

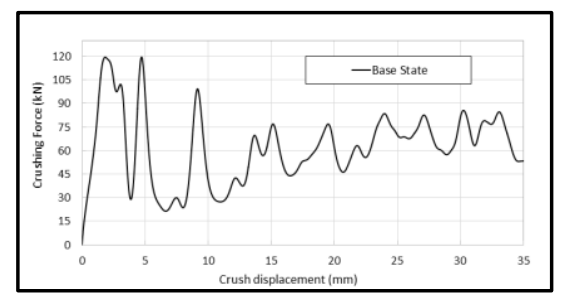




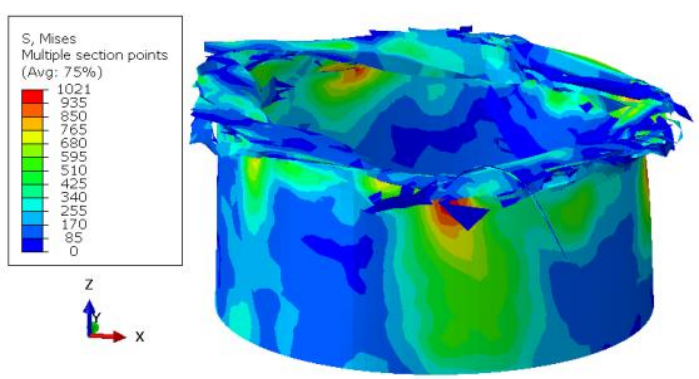

Figure 11. Stress and Compression state of base design

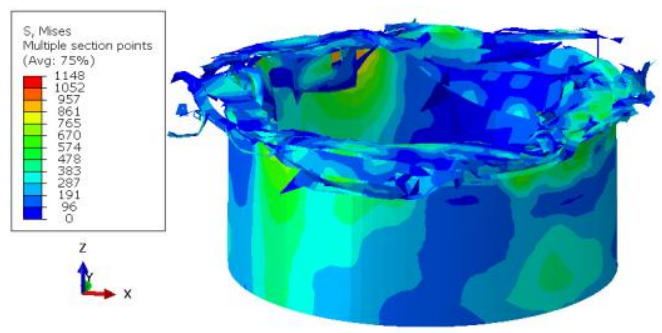

Figure 13. Stress and Compression state of post tensioned design

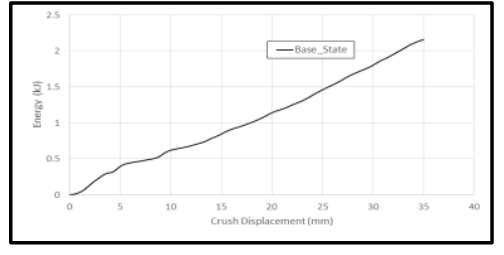

Figure 12. Force defection \& Energy absorption curve for the base design
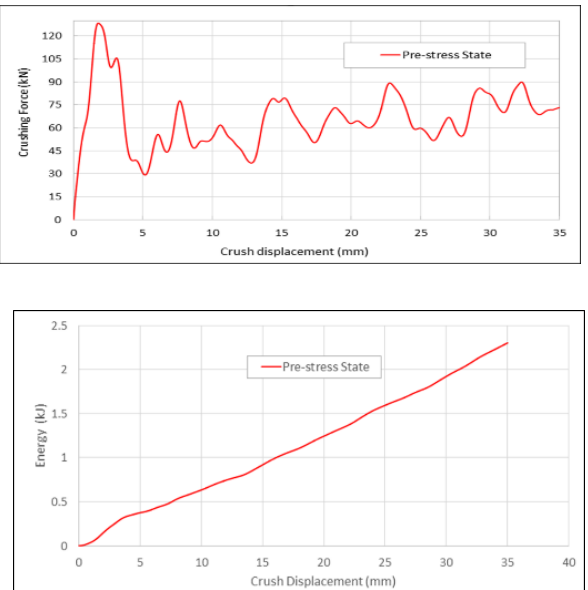

Figure 14. Force defection \& Energy absorption curve for post tensioned design

\section{COMPARISON OF BASE AD POST TENSTIONED DESIGNS}

Figure 15 gives a comparison of force-displacement curves between the base design and posttensioned designs.

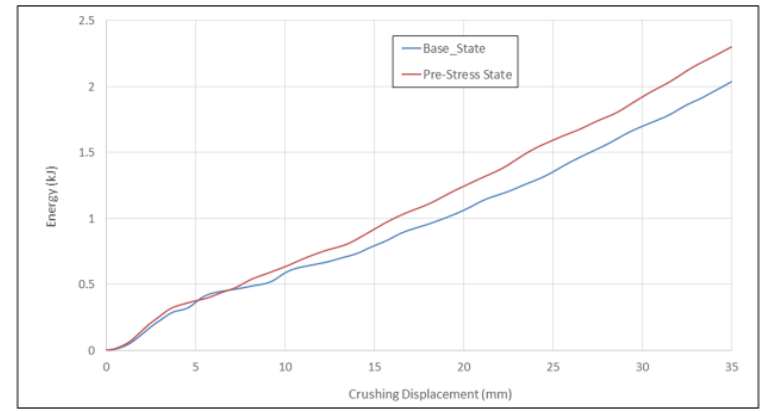


Figure 15. Comparison of force Vs displacement curves for base and post tensioned designs

\section{DISCUSSION ON RESULTS}

As can be seen from the results for the same length of compression, the post-tensioned tube can absorb more energy for the same shape/size and weight. For the sake of calibration of the Abaqus tool based on reference (Guohua Zhu et al., 2018), the compression is taken as 35 mm. However, if the compression or stroke length (M.S. Zahran et al., 2017) is more, the posttensioned design can absorb more than $10 \%$ energy compared to the base design. Also, the value of pressure has been limited to $2 \mathrm{MPa}$ (Gattineni V et al., 2020), to avoid any fatality to humans in the vicinity. If the material has more fracture energy as its property, the value of pressure can be further increased to get more benefits through post-tensioning.

\section{CONCLUSIONS}

- A finite element-based design validation method to validate the designs of post-tensioned thin CFRP tubes has been developed and presented. As can be seen from the results posttensioning in the form of applied pressure load can lead to improved energy absorption capacity for the automotive crush can

- The current values of compression and pressure can be further enhanced based on practical and safety considerations. Improved energy absorption capacity for the same weight of the tube shall result in improvement of occupant protection inside a vehicle

\section{REFERENCES}

Park, C.K., Steve, C.D., William. K., Hollowell, T., Hill, S.I. 2013. Investigation of Opportunities for Lightweight Vehicles Using Advanced Plastics and Composites. Report Number Dot Hs 811 692, National Highway Traffic Safety Administration, USA. 
Hammarberg, S., Larsson, S., Kajberg, J. et al. Numerical evaluation of lightweight ultra-high strength steel sandwich for energy absorption. SN Appl. Sci. 2, 1876 (2020). https://doi.org/10.1007/s42452-020-03724-9

T. J. Reddy, Y. V. D. Rao and V. Narayanamurthy , Evolution of a new geometric profile for an ideal tube inversion for crash energy absorption, International Journal of Mechanical Sciences 155 (2019) 125-142

T. J. Reddy, Y. V. D. Rao and V. Narayanamurthy, Thin-walled structural configurations for enhanced crashworthiness, INTERNATIONAL JOURNAL OF RASHWORTHINESS, 2017

Veerat Srilaxmi, K. Manju, M Vijaya, A case study on pre-tensioning \& post tensioning systems of a pre-stressed concrete, Int. J. Eng. Technol. Manag. Res., ISSN: 2454-1907, DOI : $10.5281 /$ zenodo/1198970 (2018)

R.S. Khurmi, N. KhurmiStrength of Materials (Mechanics of Solids) Revised Edition S Chand publishers (2018), 978-81-219-2822-2. Copyright@1968

T.Hou, B.G.Prusty, G.Pearce, D.Kelly and R. Thomson, Experimental investigation on energy absorbing pressurised composite tubes, The 19th International Conference on Composite Materials

Venkateswarlu Gattineni, Venukumar Nathi, Pre-stressed thin tubular composite energy absorbers for improved impact energy absorption, Results in Engineering, Volume 5, 2020, 100102, ISSN 2590-1230, https://doi.org/10.1016/j.rineng.2020.100102.

Budynas, Richard G., J. Keith Nisbett, and Joseph Edward Shigley. Shigley's Mechanical Engineering Design. New York: McGraw-Hill, 2011.

Guohua Zhu, Guangyong Sun, Guangyao Li, Aiguo Cheng, Qing Li, Modeling for CFRP structures subjected to quasi-static crushing, Composite Structures, Volume 184,2018, Pages 41-55,ISSN 0263-8223, https://doi.org/10.1016/j.compstruct.2017.09.001. 
Yan Ma, Shanshan Jin \& Songlin Zhang (2018): Effect of trigger on crashworthiness of unidirectional carbon fiber reinforced polyamide 6 composites, Plastics, Rubber and Composites, DOI: 10.1080/14658011.2018.1466502

Deepak Siromani, Gary Henderson, Doug Mikita, Kevin Mirarchi, Ryan Park, John Smolko, Jonathan Awerbuch, Tein-Min Tan , An experimental study on the effect of failure trigger mechanisms on the energy absorption capability of CFRP tubes under axial compression, $\quad$ Composites: $\quad$ Part $\quad$ A $\quad 64 \quad$ (2014) 25 5,http://dx.doi.org/10.1016/j.compositesa.2014.04.019

Gattineni V., Nathi V. (2020) Influence of Triggers on the Damage Characteristics and Initial Peak Load of Composite Tubular Energy Absorbers for Low-Velocity Impact Applications. In: Praveen Kumar A., Dirgantara T., Krishna P.V. (eds) Advances in Lightweight Materials and Structures. Springer Proceedings in Materials, vol 8. Springer, Singapore. https://doi.org/10.1007/978-981-15-7827-4_4

Abaqus Theory Manual, Version 19.0

Tuljapure, S.B., Sarawade, S.S. 2013. Critical Review of Study Of Crushing Tubes. International Journal of Mechanical Engineering And Technology (Ijmet), 4 (6).

HashinZ, Failure criteria for unidirectional fiber composites ASME J. Appl. Mech., 47 (2) (1980), pp. 329-334

Sun, C.T., Quinn, B.J., Tao, J., Oplinger, D.W, 1996. Comparative Evaluation of Failure Analysis Methods For Composite Laminates, Report Number Dot/Faa/Ar-95/109, U.S. Department Of Transportation Federal Aviation Administration.

\section{M.S. Zahran, P. Xue, M.S. Esa, M.M. Abdelwahab , Guoxing Lu , A New} Configuration of Circular Stepped Tubes Reinforced with External Stiffeners to Improve Energy Absorption Characteristics Under Axial Impact, Latin American Journal of Solids and Structures 14 (2017) 292-311 
Kyoung-Su Im, Zeng-Chan Zhang, and Grant O. Cook, Jr., Airbag Inflator Models in LS-DYNA®, Livermore Software Technology Corp., Livermore, CA 94551, USA, $14^{\text {th }}$ International LS-DYNA Users Conference, Session: Occupant Safety

Gattineni V., Nathi V. Finite Element Based Design Approach for Piezoelectric Pressure Sensors for Accelerated Side Crash Detection and Improved Safety, International Journal of Mechanical and Mechatronics Engineering, 2020-10-20, ISSN 2077124X, 22272771

Zhang C, Song W, Wang Q, Liu W. Influence of Pre-Stress Magnitude on Fatigue Crack Growth Behavior of Al-Alloy. Materials (Basel). 2018;11(8):1267. Published 2018 Jul 24. doi: $10.3390 / \mathrm{ma1} 1081267$

W. Werchniak, Effect of prestress on low-cycle fatigue, Engineering Fracture Mechanics, Volume 4, Issue 4, 1972, Pages 841-851, ISSN 0013-7944, https://doi.org/10.1016/00137944(72)90019-7 